\title{
Effect of surgery on motor recovery following traumatic spinal cord injury
}

\author{
RL Waters, RH Adkins, JS Yakura and I Sie \\ Regional Spinal Cord Injury Care System of Southern California, Rancho Los Amigos Medical Center, California, \\ USA
}

The influence of spine surgery on motor recovery between 1 month and 1 year was assessed prospectively in a group of 269 patients following traumatic spinal cord injury (SCI) using the classification system originally developed by the American Spinal Injury Association. The Allen classification was used to categorize cervical vertebral pathology and the Denis system was used for injuries to the thoracic and lumbar spine. Gunshot injuries were classified based upon the bullet trajectory and location relative to the spinal canal. Individuals undergoing surgery were divided into various subgroups depending on the type of surgery performed: anterior decompression with or without spine fusion and instrumentation, posterior decompression/laminectomy with or without spine fusion and instrumentation and spine fusion with instrumentation. Motor score recovery between 1 month and 1 year after injury was highly dependent $(P \leqslant 0.001)$ on the level and completeness of injury averaging $0.7 \pm 2.7$ for complete paraplegics, $7.8 \pm 4.8$ for complete tetraplegics, $11.8 \pm 8.3$, for incomplete paraplegics and 22.2 \pm 10.9 for incomplete tetraplegics. Motor recovery did not significantly differ between patients categorized in various surgical subgroups or between those having surgery and those treated non-operatively. Additionally, although the sample size was small, motor recovery among tetraplegic individuals did not depend on whether unilateral and bilateral facet dislocations were reduced and in patients with incomplete lesions, those with reductions actually had a poorer outcome than those who were left in a dislocated position.

Keywords: spinal cord injury; motor recovery; surgical treatment

\section{Introduction}

Since the introduction of Harrington Rods, continuing improvement in spinal instrumentation over the past several decades has led to reliable methods of achieving spine stability following spine fractures and dislocations. ${ }^{1,2}$ Realignment and stabilization of the spine with the appropriate instrumentation protects the spinal cord from further injury and permits both rapid mobilization of a spinal cord injured (SCI) individual out of bed and participation in the rehabilitation program. ${ }^{2}$

In addition to spine fusion and instrumentation, some surgeons believe decompression of the spinal canal is mandatory for proper care and improves the chance for neurological recovery. ${ }^{3,4}$ Others do not favor decompression unless certain conditions are present, primarily progressive neurological decline. ${ }^{5}$

Those who advocate the conservative surgical approach, i.e., no decompression unless special

Correspondence: RL Waters, M.D. Clinical Professor of Orthopedic Surgery, University of Southern California, Rancho Los Amigos Medical Center HB-117, 7601 E. Imperial Highway, Downey, CA 90242 conditions warrant, believe that the retention of bone or disc fragments in the spinal canal does not influence neurological recovery and that the risks associated with surgery outweigh uncertain benefits of surgical decompression. ${ }^{5}$ It has been recently demonstrated that bone remodeling restores canal patency in some cases. $^{6}$

Clinically, the question of whether surgical decompression improves motor recovery following SCI remains surrounded by controversy. In 1985, we began a long term study to prospectively determine the natural history of neurological recovery following SCI. This report analyzes the influence of surgical treatment on motor recovery.

\section{Methods}

Examinations for motor and sensory function were prospectively performed on 269 consecutive traumatic SCI patients admitted to Rancho Los Amigos Medical Center between 1985 and 1990 according to procedures reported previously. ${ }^{7-10}$ None of these patients received methylprednisolone according to the protocol of Bracken and associates. ${ }^{11}$ Among patients who 
received surgical treatment for their SCI, only those who underwent surgery in the first 3.5 months following injury were included in the study. Each patient's radiographs (plain films, CT and MRI where appropriate) were also examined to classify fracture type and in gunshot wound injuries, bullet location. The Allen classification was used for cervical spine injuries and the Denis system was used for injuries to the thoracic and lumbar spine. ${ }^{12,13}$ Gunshot injuries were classified based upon the bullet location relative to the spinal canal. ${ }^{14}$ In each case, the radiographs were reviewed by the research team for consensus. Type of injury (penetrating or non-penetrating) and classification of injury (fracture classification or in the case of gunshot, bullet trajectory/location) were determined for each subject.

One examiner (JY) performed all of the neurological examinations. Inter-rater reliability between the primary examiner and back-up examiners was assessed periodically as a quality assurance measure for consistency. Overall reliability for motor examinations was extremely high $(r=0.9912)$.

Since previous studies have demonstrated that motor recovery is dependent on the level and completeness of injury, patients were assigned to one of four categories: complete paraplegia, incomplete paraplegia, complete tetraplegia, and incomplete tetraplegia. ${ }^{7-10}$ Within each of the subgroups, patients were assigned to one of five categories depending on the type of treatment received: no surgery; spine fusion with instrumentation; anterior decompression with or without spine fusion and instrumentation; laminectomy/posterior decompression with or without internal instrumentation and fusion; and bullet removal. This classification system for the treatment of spinal pathology is the same as is utilized for the analysis of the national Model SCI Systems database in the United States. ${ }^{15}$ The results are presented in accord with the organization of the analyses.

\section{Results}

Between 1 month and 1 year after injury, motor recovery was highly dependent on the level and completeness of injury averaging $0.7 \pm 2.7$ for complete paraplegics, $7.8 \pm 4.8$ for complete tetraplegics, $11.8 \pm 8.3$ for incomplete paraplegics and $22.2 \pm 10.9$ for incomplete tetraplegics. The difference between these groups was highly significant $(P \leqslant 0.001)$. Accordingly, further analyses of the effect of surgical treatment were performed in each of these subgroups.

\section{Paraplegia}

There were 177 individuals with injuries resulting in paraplegia. One hundred and twenty seven individuals sustained complete injuries and 50 had incomplete injuries.

The most common cause of injury was gunshot wound ( 84 cases) followed by motor vehicle crash (38 cases), falls ( 24 cases), motorcycle accidents (16 cases) and stabs (three cases). Miscellaneous causes accounted for 12 cases.

The most common fracture pattern was fracture dislocation (35 cases) followed by burst fracture (31 cases) and compression fracture (14 cases). The fracture pattern could not be determined in 10 cases. Among individuals with gunshot wounds the bullet was lodged in the canal in 25 cases, traversed the canal in 31 cases and never entered the canal in 25 cases. Bullet location could not be determined in three cases.

Treatment and motor recovery Of the patients with non-penetrating injuries, 12 underwent anterior decompression, 10 received laminectomy/posterior decompression and 45 were treated by a spinal fusion. Of the patients with gunshot wounds, 10 had bullets surgically removed from the spinal canal Finally, 100 patients were treated by various nonoperative methods including bedrest, closed reduction and/or external immobilization.

The type of surgical treatment did not influence motor recovery in either complete or incomplete patients. Motor recovery averaged $0.7 \pm 2.7$ among complete paraplegics and $11.8 \pm 8.3$ for incomplete paraplegics. There were no significant differences in the amount of motor recovery between patients treated non-operatively or operatively or among those in the different surgical categories (Table 1).

\section{Tetraplegia}

Ninety two individuals sustained lesions resulting in tetraplegia. There were 46 complete lesions and 46 incomplete injuries.

Motor vehicle accidents were the most common cause of injury (34 cases) followed by gunshot wounds (21 cases). Other etiologies were falls (14 cases), motorcycle accidents (five cases), stabs (two cases) and miscellaneous causes (16 cases). The miscellaneous cases included diving, surfing, other sport injuries and blunt injuries from assault.

Of the non-penetrating injuries 27 were of the distractive flexion type (11 unilateral) facet dislocation, 16 bilateral facet dislocation), 14 were compressive flexion, 12 were vertical compression, five were compressive extension, one was distractive extension, 10 were due to spondylosis without evidence of fracture and five others could not be classified. Among patients with gunshot wounds, five had the major bullet fragment located inside the spinal canal, nine had the bullet located outside the canal and in eight cases the bullet had passed through the canal.

Treatment and motor recovery Forty-two patients received non-operative treatment. Eleven patients underwent anterior decompression, 29 received fusion only and six individuals underwent laminectomy/ posterior decompression. Of the individuals with gunshot wounds, four had the bullet surgically removed. 
Table 1 Paraplegia: ASIA motor score increase* between one month and one year and days to surgery**

\begin{tabular}{|c|c|c|}
\hline - & Complete SCI & Incomplete SCI \\
\hline No surgery & $\begin{array}{c}0.4 \pm 1.8 \\
n=77\end{array}$ & $\begin{aligned} 13.3 & \pm 8.8 \\
n & =23\end{aligned}$ \\
\hline Anterior decompression & $\begin{array}{c}1.8 \pm 4.0 \\
\text { median } 18(3-81) \\
n=5\end{array}$ & $\begin{array}{c}9.0 \pm 5.4 \\
\text { median } 38(2-56) \\
n=7\end{array}$ \\
\hline Fusion only & $\begin{array}{c}1.0 \pm 3.4 \\
\text { median } 15(2-47) \\
n=35\end{array}$ & $\begin{array}{c}11.2 \pm 10.7 \\
\text { median } 8.5(0-30) \\
n=10\end{array}$ \\
\hline Bullet removal & $\begin{array}{c}0.0 \\
\text { median } 4(0-14) \\
n=3\end{array}$ & $\begin{array}{c}12.1 \pm 5.8 \\
\text { median } 18(0-44) \\
n=7\end{array}$ \\
\hline $\begin{array}{l}\text { Laminectomy/posterior } \\
\text { decompression }\end{array}$ & $\begin{array}{c}3.3 \pm 5.8 \\
\text { median } 0(0-45) \\
n=7\end{array}$ & $\begin{array}{c}12.7 \pm 7.8 \\
\text { median } 11(5-38) \\
n=3\end{array}$ \\
\hline All surgical patients & $\begin{array}{c}1.32 \pm 3.8 \\
n=50\end{array}$ & $\begin{array}{r}11.03 \pm 7.7 \\
n=27\end{array}$ \\
\hline All patients & $0.7 \pm 2.7$ & $11.8 \pm 8.3$ \\
\hline
\end{tabular}

*ASIA motor score (mean and one standard deviation). ${ }^{* *}$ Days from injury to surgery: median and range

Table 2 Tetraplegia: ASIA motor score increase* between one month and one year and days to surgery**

\begin{tabular}{lcc}
\hline & Complete SCI & Incomplete SCI \\
\hline No surgery & $8.3 \pm 5.8$ & $21.6 \pm 9.9$ \\
& $n=18$ & $n=24$ \\
Anterior decompression & $8.3 \pm 6.1$ & $21.0 \pm 13.5$ \\
& median $78.5(10-105)$ & $n=5$ \\
Fusion only & $n=6$ & $21.7 \pm 13.1$ \\
& $7.3 \pm 3.5$ & median $15(2-75)$ \\
& median $7(0-56)$ & $n=11$ \\
Bullet removal & $n=18$ & $29.5 \pm 12.0$ \\
& $10.0 \pm 2.8$ & median $45(1-89)$ \\
Laminectomy/posterior & median $23(15,31)$ & $n=2$ \\
decompression & $n=2$ & $24.8 \pm 12.2$ \\
& $10.5 \pm 3.5$ & median $20.5(0-41)$ \\
All surgical patients & median $6.5(5,8)$ & $n=4$ \\
All patients & $n=2$ & $22.8 \pm 12.3$ \\
\end{tabular}

*ASIA motor score (mean and one standard deviation). ${ }^{* *}$ Days from injury to surgery in parentheses (mean and one standard deviation)

There was no difference in the ASIA Motor Score recovery between patients treated non-operatively and those treated surgically. ASIA Motor Score recovery among patients with complete tetraplegia averaged $7.8 \pm 4.8$ points and $22.2 \pm 10.9$ for those with incomplete tetraplegia. As with paraplegic individuals further division of tetraplegic patients according to type of surgery performed did not demonstrate any significant differences (Table 2).

Among patients sustaining cervical distractive flexion injuries causing unilateral or bilateral facet dislocation, the effect of reduction of the dislocation on motor recovery was examined by calculating the total Motor Score recovery as well as the amount of motor recovery at the level of dislocation ('first root') and at the next caudal root ('second root'). The distribution of levels of dislocation were as follows: two at $\mathrm{C} 3 / \mathrm{C} 4$, five at $\mathrm{C} 4 / \mathrm{C} 5,11$ at $\mathrm{C} 5 / \mathrm{C} 6$, eight at $\mathrm{C} 6 /$ $\mathrm{C} 7$ and one at $\mathrm{C} 7 / \mathrm{T} 1$.

There were no significant differences between those patients whose dislocations were not reduced and those in whom reduction was performed at the first or second roots (Table 3). Among those with incomplete lesions, total motor recovery was greater in the three patients who remained dislocated compared to those whose dislocations were reduced. 
Table 3 Distraction flexion injuries: ASIA motor score increase* between one month and one year and number of days to reduction

\begin{tabular}{lcccc}
\hline & Days to reduction** & First root & Second root & Total \\
\hline $\begin{array}{c}\text { Complete tetraplegia } \\
\text { unreduced } n=9\end{array}$ & - & $1.7 \pm 1.2$ & $0.1 \pm 0.2$ & $6.1 \pm 4.6$ \\
$\begin{array}{c}\text { Complete tetraplegia } \\
\text { reduced } n=8\end{array}$ & $19.9 \pm 24.84$ & $1.1 \pm 1.0$ & $0.4 \pm 1.0$ & $8.4 \pm 3.4$ \\
$\begin{array}{c}\text { Incomplete tetraplegia } \\
\text { unreduced } n=4\end{array}$ & $6.00 \pm 5.93$ & $1.3 \pm 0.9$ & $1.3 \pm 1.2$ & $23.5 \pm 9.4$ \\
$\begin{array}{c}\text { Incomplete tetraplegia } \\
\text { reduced } n=6\end{array}$ & $1.1 \pm 1.2$ & $1.1 \pm 1.2$ & $18.7 \pm 12.4$ \\
\hline
\end{tabular}

*ASIA Motor Score (mean and one standard deviation). ${ }^{* *}$ Mean and one standard deviation

\section{Discussion}

In response to the need to more accurately assess neurological recovery, the American Spinal Injury Association (ASIA) developed standards for neurological testing in 1982. ${ }^{16}$ In conjunction with ASIA, these standards underwent further revision and were jointly endorsed by the International Medical Society of Paraplegia in Barcelona in 1992. ${ }^{17}$ These standards provide the most valid, precise and reliable minimum data set. ${ }^{18}$ This study is the largest prospective evaluation of surgical outcomes in SCI patients utilizing these standards.

The majority of neurological recovery occurs between 1 month and 1 year and any positive effects of surgery on motor recovery should be demonstrable in this time interval. ${ }^{7-10}$ The 1 month examination point was utilized as the initial measurement point because the motor examination is highly repeatable and reliable at this time while earlier examinations can be unreliable and more difficult to perform. ${ }^{7,19}$

We have previously demonstrated that motor recovery between $\mathrm{r}$ month and 1 year is independent of the type of spinal cord pathology when controlled for the level and completeness of SCI. ${ }^{20}$ Motor recovery was the same whether SCI resulted from the concussive impact of a bullet to the vertebra without penetration of the spinal canal or from a burst fracture with bone and disc fragments occluding the spinal canal. ${ }^{20}$ Since the presence or absence of spinal occlusion based on etiology makes no difference to motor outcome, it is not surprising that surgical decompression of bone fragments within the spinal canal to restore canal patency also does not influence motor recovery when controlled for the level and completeness of injury.

Failure to demonstrate a positive effect of surgery or reduction of cervical dislocations on motor recovery may be related to the time interval between injury and treatment (surgery or reduction of cervical dislocations). It is possible that if surgical decompression or reduction of cervical dislocations had been performed immediately after injury, a positive benefit would have been observed. In this series, the average time to surgical decompression was more than 14 days following injury and reduction of cervical dislocations more than 6 days. The necessity for early intervention to affect neurological recovery is supported by the findings of Bracken and associates in which methylprednisolone was found to be beneficial only if administered within $8 \mathrm{~h}$ following injujry. ${ }^{11}$

Since this study was conducted at a rehabilitation center and not in the acute hospital setting, surgeries were performed by a variety of surgeons at different hospitals. Therefore the investigators were not able to perform a controlled study of the effects of surgery. The majority of the surgical procedures, however, were performed at major university teaching hospitals in the Los Angeles area.

There are many different subcategories of injury and fracture type. Nevertheless in this series, there were insufficient numbers of cases to separately analyze the effects of decompression in specific fracture types. Although it is possible that decompression might be beneficial in only certain types of injuries, we were unable to adequately test this hypothesis. In addition to an insufficient number of cases to test the hypothesis, there is also the problem of appropriate research design. This study was not designed specifically to test the effects of surgery but the recovery process given current clinical practices. Because of the difficulty of a single center prospectively collecting a sufficient number of cases of a specific injury type, multicenter studies are necessary. Such a study was performed to determine the effects of bullet removal from the spinal canal. ${ }^{21}$ This study revealed that the effects of surgical decompression of bullets on motor recovery was dependent on the level of injury. Delamarter and associates have demonstrated resolution of neurological deficits after decompression of chronic constrictive occlusion of the nerve roots of the cauda equina in beagles. ${ }^{22}$ In this series, there was an insufficient number of cases having initial neurological injury at or below $\mathrm{T} 12$ to perform statistical analysis for the various subgroups based on anatomical level. 


\section{Acknowledgements}

Funded in part by the National Institute of Disability and Rehabilitation Research, Field Initiated Research Grant Nos. G008435028 and H133G901 15.

\section{References}

1 Cotler JM, Vernace JV, Michalski JA. The use of Harrington rods in thoracolumbar fractures. Orthopedic Clinics of North America 1986; 17: $87-103$.

2 Cotler HB. The treatment of cervical spine trauma: a century of progress. Orthopaedics 1992; 5: 279-283.

3 Bradford DS, McBride GG. Surgical management of thoracolumbar spine fractures with incomplete neurological deficits. Clinical Orthopaedics and Related Research 1987; 218: 201.

4 Bohlman $\mathrm{HH}$, Freehafer A, Dejak J. The results of treatment of acute injuries of the upper thoracic spine with paralysis. $J B J / S$ 1985; 67A: 360.

5 Crutcher JP et al. Indirect spinal canal decompression in patients with thoracolumbar burst fractures treated by posterior distraction rods. J Spinal Dis 1991; 4: 39 -- 48.

6 Mumford J et al. Thoracolumbar burst fractures: The clinical efficacy and outcome of nonoperative management. Spine 1993; 18: $955 \cdots 970$.

7 Waters RL et al. Recovery following complete paraplegia. Arch Phys Med Rehabil 1992; 73: $784-789$.

8 Waters RL et al. Motor and sensory recovery following complete tetraplegia. Arch Phys Med Rehabil 1993; 74: 242 -- 247.

9 Waters RL et al. Motor and sensory recovery following incomplete paraplegia. Arch Phys Med Rehabil 1994; 75: 67-72.

10 Waters RL et al. Neurologic recovery following incomplete tetraplegia. Arch Phys Med Rehabil 1994; 75: $306-311$.

11 Bracken MB et al. A randomized, controlled trial of methylprednisolone or naloxone in the treatment of acute spinal-cord injury. Results of the Second National Acute Spinal Cord Injury Study. New Eng J Med 1990; 322: 1405 - 1411
12 Allen BL et al. A mechanistic classification of closed indirect fractures and dislocations of the lower cervical spine. Spine 1982; 7: $1-27$.

13 Denis F. The three column spine and its significance in the classification of acute thoracolumbar spine injuries. Spine 1983; 8: $817-831$.

14 Waters RL et al. Profiles of spinal cord injury and neurologic recovery following gunshot. Clin Orthop 1991; 267: 14-21.

15 Stover SL, DeLisa JA, Whiteneck GG. Spinal Cord Injury Clinical Outcomes from the Model Systems. Gaithersburg, MD: Aspen Publishers, Inc., 1995.

16 Standards for Neurological Classification of Spinal Injury Patients. American Spinal Injury Association 1985; Chicago, Illinois.

17 Ditunno JF. The international standards booklet for neurological and functional classification of spinal cord injury. Paraplegia 1994; 32: $70-80$.

18 Capaul M et al. Analyses of 94 consecutive spinal cord injury patients using ASIA definition and modified Frankel score classification. Paraplegia 1994; 32: $583-587$.

19 Brown PJ et al. The $72 \mathrm{~h}$ examination as a predictor of recovery in motor complete quadriplegia. Arch Phys Med Rehabil 1991; 72: 546 -- 548.

20 Waters RL et al. Effect of Injury Pattern on Motor Recovery following Traumatic SCI. Arch Phy's Med Rehabil 1995; 76: 440 443.

21 Waters RL, Adkins RH. The effects of removal of bullet fragments retained in the spinal canal. A collaborative study by the National Spinal Cord Injury Model Systems. Spine 1991; 16: $934-939$.

22 Delamarter RB, Sherman JE. Carr JB. 1991 Volvo Award in Experimental Studies, Cauda Equina Syndrome: Neurologic recovery following immediate, early, or late decompression. Spine 1991; 16: $1022-1029$ 